Article

\title{
O Conhecimento sobre Sismos e Mudanças Climáticas como Proposta Pedagógica: Estudo de Caso em uma escola Pública de Fortaleza/CE
}

\author{
Emerson Mariano da Silva ${ }^{1}$ (D), Karina Karla Frota de Albuquerque ${ }^{1}$, Jose Maria Brabo Alves ${ }^{1}$, \\ Francisco das Chagas Brandão Melo ${ }^{2}$ \\ ${ }^{1}$ Mestrado Profissional em Climatologia e Aplicações nos Países da CPLP e África, Universidade \\ Estadual do Ceará, Fortaleza, CE, Brasil. \\ ${ }^{2}$ Coordenadoria Estadual de Defesa Civil, Corpo de Bombeiros Militar do Ceará, Fortaleza, CE, \\ Brasil.
}

Recebido em: 18 de Fevereiro de 2021 - Aceito em: 19 de Abril de 2021

\begin{abstract}
Resumo
Apresentam-se os resultados da aplicação de uma proposta pedagógica, baseada nos princípios norteadores da pedagogia libertadora, através da oferta de uma disciplina semestral ("No Ceará tem disso, sim!") com conteúdos sobre os sismos e sobre as mudanças climáticas para estudantes de uma escola pública em regime integral localizada em uma área de vulnerabilidade social (IDH de 0,395) em Fortaleza no Ceará. Os resultados mostraram que a adoção dessa prática pedagógica propicia além da difusão de conhecimento teórico e científico, consciência para desenvolver futuras ações que visam mitigar os riscos e os efeitos dos desastres naturais desencadeados por possíveis mudanças no clima e pela ocorrência de tremores de terra nas comunidades. Assim, o processo cooperativo de ensino-aprendizagem proporcionou a apropriação de conhecimentos sobre tremores de terra e sobre as mudanças climáticas, sendo capaz de provocar entre os estudantes participantes ações e ideias que visam sensibilizar a comunidade sobre os efeitos das alterações climáticas antropogênicas, possibilitando a formação de pessoas conscientes do seu papel na comunidade em que vivem.
\end{abstract}

Palavras-chave: ensino de climatologia, sismos, mudanças climáticas.

\section{Knowledge about Earthquakes and Climate Change as a Pedagogical Proposal: Case Study in a Public School in Fortaleza/CE}

\begin{abstract}
The results of the application of a pedagogical proposal, based on the guiding principles of liberating pedagogy, are presented, through the offer of a semester course ("Yes, in Ceará there is this!") with content on earthquakes and climate change for students from a full-time public school located in an area of social vulnerability (HDI 0.395) in Fortaleza, Ceará. The results showed that the adoption of this pedagogical practice provides, in addition to the dissemination of theoretical and scientific knowledge, awareness to develop future actions aimed at mitigating the risks and effects of natural disasters triggered by possible changes in the climate and by the occurrence of earthquakes in the communities. Thus, the cooperative teaching-learning process provided the appropriation of knowledge about earthquakes and climate change, being able to provoke among the participating students actions and ideas aimed at sensitizing the community about the effects of anthropogenic climate changes, enabling the training people aware of their role in the community in which they live.
\end{abstract}

Keywords: Teaching climatology, earthquakes, climate change.

\section{Introdução}

Estudos científicos indicam que os terremotos (sismos) sofrem influência do clima, assim, também sofrem influências das mudanças climáticas. Mudanças no clima são capazes, em longo prazo, de potencializar o movi- mento das placas tectônicas causando o aumento de incidências de tremores de terra. O inverso também pode acontecer com eventos geológicos decorrentes do mesmo fenômeno influenciando o clima por milhões de anos e com efeitos retroativos (McGuire, 2010; Liu, et al., 2009; Rubinstein et al., 2009; Heki, 2003).

Autor de correspondência: Emerson Mariano da Silva. E-mail: emerson.mariano@uece.br. 
$\mathrm{O}$ aumento da frequência de ocorrência de terremotos pode desencadear outros fenômenos de efeitos destrutivos em meios povoados, como tsunamis, inundações por explosões de lagos glaciais, deslizamentos marinhos e outras.

O Brasil localiza-se sobre o interior de uma placa tectônica, a Placa Sul-Americana, apresenta atividade sísmica em seu território considerada baixa comparando-se com outros países da América do Sul que estão localizados próximos dos limites territoriais das bordas dessa placa tectônica. Entretanto, engana-se quem acredita que abalos sísmicos não acontecem com frequência no país.

Durante um longo período os abalos sísmicos não foram registrados em sua totalidade no país, acredita-se que isso é devido à grande extensão territorial do país, as grandes áreas de terras ainda desabitadas, ou ainda ao elevado número de localidades com baixa densidade demográfica.

Estudo realizado por Veloso (2012) atesta a ocorrência de um terremoto histórico em 1690, considerado como o de maior magnitude no país, alcançando a marca de 7,0 na escala Richter. A ocorrência deste terremoto comprova que o país pode ser afetado por terremotos mais severos, mesmo que raramente. Outro abalo sísmico de significância registrado no país ocorreu no Mato Grosso no ano de 1955, atingindo 6,2 de magnitude na escala Richter.

No Ceará a sismicidade é caracterizada como notável, as probabilidades de ocorrerem abalos de terra com magnitude igual ou maior que 4,0 na escala Richter são elevadas e isso ocorre pelo fato do estado ser a região brasileira mais ativa em termos de taxa de atividade sísmica (número de eventos por unidade de tempo) e de continuidade de ocorrência do país. O primeiro sismo registrado no estado do Ceará ocorreu em 1807, na cidade de Pereiro, a partir de então, os tremores de terra continuam sendo registrados com frequência na região.

O maior sismo ocorrido na região Nordeste foi o "terremoto de Pacajus" no Ceará, ocorrido em 20 de novembro de 1980, com magnitude de 5,2 na escala Richter. Tremores de terra foram registrados a $600 \mathrm{~km}$ de distância do epicentro, fato que teve repercussão nacional e provocou danos estruturais em 488 (quatrocentos e oitenta e oito) habitações e incêndios na região.

Portanto, considerando a importância da ocorrência desses fenômenos associados as possíveis mudanças no clima da região, apresenta-se um estudo que visa caracterizar a ocorrência de sismos no Ceará, bem como discutir como o conhecimento sobre a frequência de ocorrência dos sismos no estado pode propiciar a redução de riscos e da vulnerabilidade da sociedade que vive nas áreas de possíveis ocorrências desses fenômenos. Especificamente, o estudo visa investigar como a educação escolar pode ser utilizada na difusão do conhecimento científico sobre abalos sísmicos, mudanças climáticas, e sobre as relações entre esses, no ambiente escolar.

\subsection{Abalos sísmicos e mudanças climáticas}

A relação entre mudanças climáticas, sejam de origem natural ou antropogênica, e abalos sísmicos tem sido alvo de diversas pesquisas científicas realizadas nas últimas décadas. McGuire (2010) cita vários desses estudos ao redor do mundo que mostram os efeitos devastadores da ocorrência de terremotos lentos, como é o caso do ocorrido em Taiwan (Liu et al., 2009) na região noroeste do Oceano Pacífico e no Japão (Rubinstein et al., 2009; Heki, 2003).

Ao analisar os efeitos geológicos e geomorfológicos das mudanças climáticas de caráter antropogênico, notadamente do aquecimento global, McGuire (2010) sugere que o aumento dos riscos geológicos e geomorfológicos representa uma resposta da geosfera a essas mudanças no clima.

Outros estudos corroboram com essa hipótese, ou seja, a medida que se tem aumento das calotas polares e da formação do gelo em lagos o escorregamento e a sismicidade de falhas tectônicas diminuem, assim, o inverso também é possível ocorrer, com o aquecimento e o aumento da temperatura do ar nos polos, que por sua vez leva ao derretimento anômalo das calotas polares, a atividade sísmica na região pode aumentar (Hampel, Hetzel e Maniatis, 2010).

Iaffaldano et al. (2011) e McGuire (2010), indicam que a variação na intensidade das monções impacta no movimento das placas tectônicas e que o aumento das chuvas de monções tornou mais frequente os deslizamentos de terra no Himalaia, em consequência disso tem-se o aumento da atividade sísmica na região.

Os estudos supra citados atestam que as mudanças no clima afetaram o funcionamento da geosfera no passado, em períodos de transição entre a glaciação e a deglaciação. Além disso, apresentam vários indicativos de que o aquecimento global atual, e de caráter antropogênico, é capaz de desencadear inúmeros desastres naturais, destacadamente fenômenos sísmicos com efeitos destrutivos para a humanidade. Assim, fica evidente que a humanidade necessita do conhecimento sobre os efeitos causados pelos sismos, das mudanças climáticas e da relação entre esses fenômenos, para assim ter a possibilidade de desenvolver um modo de vida sustentável que possa garantir a existência de um futuro para as gerações vindouras (Krenak, 2019).

\subsection{A relação entre o conhecimento e a redução da vulnerabilidade sísmica}

A partir do ano de 2018 a educação escolar no país iniciou o processo de implementação da Base Nacional Comum Curricular (BNCC), trata-se de um documento de caráter normativo que define o conjunto de aprendizagens essenciais que todos os estudantes da educação básica (educação infantil, ensino fundamental e ensino médio) 
devem desenvolver no decorrer de suas etapas e modalidades, assegurando os seus direitos de aprendizagem e desenvolvimento.

Aplicando-se exclusivamente à educação escolar, a BNCC visa à formação humana integral e à composição de uma sociedade democrática, inclusiva e justa. As aprendizagens essenciais constantes no documento devem garantir aos estudantes o desenvolvimento de competências gerais, que se desdobram no tratamento didático proposto ao longo das etapas da Educação Básica. Nesse contexto, competência é definida de acordo com a BNCC como a mobilização de conhecimentos, habilidades, atitudes e valores para resolver questões intricadas da vida cotidiana, do universo do trabalho e do pleno exercício da cidadania.

Em suma, a BNCC se afirma como um mecanismo essencial na melhoria da qualidade da educação nacional, que, com a colaboração da sociedade pode ser capaz de despertar os jovens para o exercício da cidadania com autonomia, resultando em mais qualidade de vida em nossa sociedade.

Acredita-se que o modelo educacional baseado na pedagogia libertadora é necessário para que crianças e adolescentes possam apropriar-se o quanto antes da sua realidade e daquilo que acontece no seu entorno, como os sismos, e compreendam o seu papel de agente capaz de interferir e modificar determinadas condições que os deixam em situação vulnerável. Assim, representariam o que se espera de cidadãos responsáveis, autônomos e conscientes da participação que devem ter na constituição da sociedade.

Dessa forma, o estudo dos conceitos de climatologia nas escolas, objetivando o despertar de uma consciência ambiental por parte do corpo discente, também é essencial no processo de formação cidadã proposto. Os hábitos de consumo da nossa sociedade contemporânea acarretam grandes emissões de Dióxido de Carbono $\left(\mathrm{CO}_{2}\right)$ que por sua vez possibilitam mudanças no clima de algumas regiões, denominadas de mudanças climáticas, como por exemplo, o aumento de temperatura nos oceanos que influenciam no derretimento das calotas polares, e por sua vez na elevação do nível dos oceanos e no aumento da frequência de ocorrência de fenômenos como os terremotos, tsunamis e outros.

A compreensão da necessidade de mudanças dos hábitos de consumo da atual sociedade e da importância do desenvolvimento sustentável a nível global é imprescindível para impulsionar a realização de ações que garantam que as gerações mais jovens tenham seu futuro assegurado no planeta.

Entender as causas dos sismos e sua imprevisibilidade além dos fatores que influenciam na vulnerabilidade da população frente a um abalo sísmico permite que as pessoas saibam agir de modo preventivo, efetivo e imediato, para que evitem a ocorrência de maiores desastres.
Essa compreensão ampla de mundo, partindo das demandas locais até as esferas maiores pode e deve ser alcançada através da pedagogia libertadora aplicada na educação escolar.

Conforme o Ministério das Cidades (2007), vulnerabilidade é o "grau de perda para um dado elemento, grupo ou comunidade, dentro de uma determinada área passível de ser afetada por um fenômeno ou processo".

Entre os fatores que aumentam a vulnerabilidade sísmica de um grupo ou sociedade, tem-se: situação socioeconômica de pobreza ou extrema pobreza, a ausência de representatividade política, o estabelecimento em áreas de risco ou em ambientes deteriorados, as construções frágeis, o desconhecimento frente a um perigo real e a ausência de ações do Estado que promovam a resiliência.

Ainda há dentro da população em geral, grupos específicos que se tornam mais vulneráveis aos desastres naturais como mulheres e crianças que segundo Freitas et al. (2012) apresentam 14 vezes mais chances de óbito no caso de desastres dessa natureza.

Esse é um dado que justifica a promoção da educação e a disseminação do conhecimento, especialmente frente às crianças e a formação da cidadania com o desenvolvimento junto à população de uma cultura de prevenção de riscos a desastres. Ou seja, utilizar a educação como um meio de reduzir a vulnerabilidade junto a um dos grupos mais fragilizados diante de um tremor de terra é um modo de minimizar os riscos associados a esses desastres.

Preve, D'Espindula e Valdati (2017) destacam que o desconhecimento de boa parcela da população brasileira para com a sismicidade é um fator que eleva os riscos e a probabilidade de geração de desastres, inclusive em caso de ocorrência de sismos com magnitudes moderada e leve (classificação pela Escala Richter). Exemplificam com uma situação registrada no estado do Maranhão, em 2017, quando um abalo de magnitude 4,7 levou ao esvaziamento de prédios trazendo despreparo a população da região.

Visando capacitar a sociedade e mitigar os efeitos associados a ocorrência dos sismos os autores sugerem a aplicação de programas educacionais nas escolas, simultaneamente à elaboração e divulgação de cartilhas de prevenção de desastres em todos os estados da federação, com conteúdos que incluam as informações sobre os terremotos e à concepção de planos de emergência coordenados pela Secretaria Nacional de Defesa Civil (Preve, D’Espindula e Valdati, 2017).

Ressalta-se que, no Estado do Ceará tem-se disponível na página eletrônica da Defesa Civil Estadual uma cartilha inteiramente voltada a disseminação dos conhecimentos sobre os tremores de terra, contendo informações sobre a sismologia mundial, brasileira e cearense, sobre as escalas Richter e Mercalli, bem como sugestões de ações preventivas e medidas a serem tomadas durante a ocorrência de sismos. 
Além disso, o Núcleo de Sismologia da Coordenadoria Estadual de Defesa Civil do Ceará (CEDEC) acompanha constantemente as atividades sísmicas no estado e encontra-se aberto à visitação de estudantes e professores, promovendo palestras sobre a compreensão dos fenômenos sísmicos e a disseminação de medidas de segurança úteis no enfrentamento de tremores de terra, que são essenciais para mitigar os danos e salvar vidas.

\section{Ocorrências de Sismos no Ceará}

"A Placa Sulamericana está submetida a um regime compressivo provocado pelo empurrão da Placa de Nazca de oeste para leste, e pela ascensão magmática na cadeia meso-atlântica, que a empurra para oeste" (Correia, 2010). Essa compressão a que está submetida a Placa Sul-Americana é a maior responsável por grande parte dos terremotos que ocorrem na região Nordeste do Brasil (NEB).

O NEB é uma região sismologicamente instável, isso pelo fato de grande parte de seu território encontrar-se sobre uma unidade geológica muito antiga e cheia de falhas, as mais extensas e profundas são nomeadas pelos geocientistas de suturas e tendem a se movimentar provocando diversos abalos sísmicos (Correia, 2010).

O território nordestino também fica localizado geograficamente próximo da falha do Oceano Atlântico Central, o que provoca uma taxa de atividade sísmica com continuidade de ocorrência mais alta do que outras regiões brasileiras. O NEB é a região que apresenta a maior atividade sísmica do Brasil, considerando sismos de magnitude até 4,9 na escala Richter. Os primeiros registros históricos de abalos sísmicos nessa área são de 1724, em Salvador BA. Desde então, muitos tremores de terra vêm ocorrendo nos estados nordestinos, destacando-se como mais atingidos: Ceará, Rio Grande do Norte, Pernambuco e Bahia.

Melo (2007) explica que a sismicidade nordestina concentra-se principalmente em torno da Bacia Potiguar (numa área de $100 \mathrm{~km}$ de largura), no Agreste Pernambucano (em torno do município de Caruaru) e no Oeste do Ceará (entre a Bacia do Parnaíba e a Potiguar). Em adição, mostra que existem extensas falhas transcorrentes précambrianas na região, ressaltando as falhas de Sobral Pedro II (CE e PI), de Pernambuco (PE) e Patos (PB).

Os principais eventos sísmicos ocorridos nas regiões do NEB foram o "terremoto de Pacajus" no Ceará (1980) e os registrados em João Câmara no Rio Grande do Norte em 1986 com magnitude de 5,1 e em 1989 com magnitude 5,0 na escala Richter.

O tremor ocorrido em João Câmara em 1986 e a continuidade da atividade sísmica na região causaram o desabamento de casas, desalojaram diversas famílias (resultando em 26.200 pessoas desabrigadas e na reconstrução ou recuperação de 4.348 imóveis) e levaram milhares de pessoas a abandonar a cidade, atraindo até a visita do então Presidente da República - José Sarney.
O Ceará é o estado do NEB que apresenta a mais expressiva atividade sísmica, de acordo com a Tabela 1 foram observados 358 (trezentos e cinquenta e oito) sismos de magnitude maior ou igual a 2,0 e menores que 5,0 na escala Richter.

Takeya (2016) explica que essa elevada atividade sísmica tem relação com as direções das grandes feições geológicas da região: "Os estudos de mecanismo focal dos sismos, ocorridos nesta região do nordeste oriental, mostram que as tensões predominantes na litosfera são de compressão horizontal, na direção leste-oeste. A hipótese, segundo a teoria da Tectônica de Placas, é a de que tais tensões são consequência do empurrão exercido pela Cadeia Meso-Atlântica. Este esforço, de compressão na direção E-W, gera mais sismos em regiões onde as grandes estruturas estão dispostas na direção sudoeste para nordeste, como é o caso das estruturas no Ceará e R.G. do Norte".

A Fig. 1 apresenta a distribuição espacial da ocorrência de tremores de terra no Ceará. Os resultados mostram que, dentre os 184 (cento e oitenta e quatro) municípios do estado, em 60 (sessenta) foram observados a ocorrência de evento sísmico, ou seja, quase um terço dos municípios cearense registraram tremores de terra.

Destaca-se que as informações apresentadas acima evidenciam a grande atividade sísmica observada no estado do Ceará, em 10 (dez) municípios dos 60 (sessenta) que registraram tremores de terra, a magnitude alcançada foi maior ou igual a 4,0 na escala Richter.

Conhecido localmente como "Terremoto de Pacajus", registrado em 20 de novembro de 1980, foi o mais intenso tremor de terra registrado nas regiões Norte e Nordeste do país, com magnitude de 5,2 na escala Richter, teve epicentro registrado na localidade de Brito no município de Cascavel/CE, com raio de $600 \mathrm{~km}$ chegando a atingir a capital do Piauí, causando e danos estruturais em 488 (quatrocentos e oitenta e oito) residências, incêndios e óbitos.

Palhano/CE, cidade localizada a $150 \mathrm{~km}$ da capital do estado, também apresenta destaque em atividade sísmica, entre os anos de 1987 e 1993 sofreu registro uma série de tremores de terra de magnitude maior ou igual a 4,0 , fato que levou pesquisadores da Universidade Federal do Rio Grande Norte (UFRN) e da Universidade de Brasília (UnB) a instalarem equipamentos registrados na região. Assim, foram registrados mais de 28 mil eventos, sendo o maior tremor ocorrido em 1989 com 4,5 de magnitude na escala Richter.

Na cidade cearense de Sobral e em seu entorno os registros de tremores são intensos. Entre 2008 e 2012, quase quatro mil tremores aconteceram no município. No ano de 2008 foi registrado na região da Serra da Meruoca, compartilhada pelos municípios de Meruoca/CE, Alcântaras/CE e Sobral/CE, um sismo de magnitude 4.3 na escala Richter. 
Tabela 1 - Registros de sismos nos municípios do Ceará (em vermelho estão os registros de sismos com magnitude igual ou maior a 4,0 na escala Richter, o H indica que a magnitude não foi confirmada).

\begin{tabular}{|c|c|c|c|c|c|c|c|c|}
\hline $\mathrm{N}^{\mathrm{o}}$ & Município & Mag & $\mathrm{N}^{\circ}$ & Município & Mag & $\mathrm{N}^{\circ}$ & Município & Mag \\
\hline 1 & Acarape & 3,0 & 21 & Guaramiranga & 2,3 & 41 & Morada Nova & 2,8 \\
\hline 2 & Aiuaba & 2,6 & 22 & Hidrolândia & 2,7 & 42 & Morrinhos & 2,9 \\
\hline 3 & Alcântaras & 3,4 & 23 & Ibaretama & 3,9 & 43 & Orós & 3,0 \\
\hline 4 & Apuiarés & 2,9 & 24 & Ibicuitinga & $\mathrm{H}$ & 44 & Pacajus & 5,2 \\
\hline 5 & Aracati & 4,0 & 25 & Icó & 3,2 & 45 & Palhano & 4,5 \\
\hline 6 & Barroquinha & 2,5 & 26 & Ipueiras & $\mathrm{H}$ & 46 & Palmácia & $\mathrm{H}$ \\
\hline 7 & Baturité & 4,1 & 27 & Irauçuba & 4,9 & 47 & Paramoti & 2,3 \\
\hline 8 & Beberibe & 2,2 & 28 & Itapajé & 3,0 & 48 & Pentecoste & 2,1 \\
\hline 9 & Brejo Santo & 2,0 & 29 & Itatira & $\mathrm{H}$ & 49 & Pereiro & 4,6 \\
\hline 10 & Camocim & 2,7 & 30 & Jaguaribara & 2,3 & 50 & Quixadá & $\mathrm{H}$ \\
\hline 11 & Canindé & $\mathrm{H}$ & 31 & Jaguaribe & 3,5 & 51 & Quixeramobim & 3,6 \\
\hline 12 & Cascavel & 4,1 & 32 & Jaguaruana & $\mathrm{H}$ & 52 & Santa Quitéria & 2,7 \\
\hline 13 & Catarina & $\mathrm{H}$ & 33 & Jardim & $\mathrm{H}$ & 53 & Santana do Acaraú & 2,1 \\
\hline 14 & Chorozinho & 3,1 & 34 & Lavras da Mangabeira & $\mathrm{H}$ & 54 & São Luiz do Curu & 3,3 \\
\hline 15 & Coreaú & 2,9 & 35 & Maranguape & 4,5 & 55 & Senador Sá & 3,2 \\
\hline 16 & Farias Brito & 3,0 & 36 & Martinópole & 2,0 & 56 & Sobral & 2,6 \\
\hline 17 & Forquilha & 2,5 & 37 & Massapê & 2,7 & 57 & Tejuçuoca & 2,8 \\
\hline 18 & Frecheirinha & 3,2 & 38 & Meruoca & 4,3 & 58 & Tianguá & $\mathrm{H}$ \\
\hline 19 & Granja & 3,0 & 39 & Mombaça & 2,5 & 59 & Ubajara & $\mathrm{H}$ \\
\hline 20 & Groaíras & 4,1 & 40 & Monsenhor Tabosa & 2,8 & 60 & Uruoca & $\mathrm{H}$ \\
\hline
\end{tabular}

Fonte: Coordenadoria Estadual de Defesa Civil do Ceará - CEDEC.

Lançado em 2011 o blog Sismos do Nordeste, iniciativa do Laboratório Sismológico (LabSis) do Departamento de Geofísica (DGEF) do Centro de Ciências Exatas e da Terra (CCET) da UFRN, representa uma importante fonte de informações sobre os abalos sísmicos que ocorrem no NEB.

Assim, os registros apontam ocorrências de uma série de sismos no Ceará, tremores de terra com magnitudes que variaram de 1,3 a 2,8 na escala Richter em 2018, eventos que chegaram à magnitude de 2,9 em 2019 no município de Quixeramobim/CE, e de 2,4 em Palhano/CE e Cascavel/CE.

\section{Materiais e Métodos}

Visando discutir como o conhecimento sobre a frequência de ocorrência dos sismos no estado do Ceará pode propiciar a redução de riscos e da vulnerabilidade da sociedade que vive nas áreas de possíveis ocorrências desses fenômenos, foi ofertada aos estudantes dos sexto e sétimo anos de uma escola pública de tempo integral (Diogo Vital de Siqueira) localizada em uma área de IDH de 0,395 em Fortaleza/CE, uma disciplina com duração semestral, intitulada "No Ceará tem disso, sim!", abordando conteúdos sobre as mudanças climáticas e sobre os abalos sísmicos, incluindo também as práticas de um plano de ação para reduzir os riscos na ocorrência dos tremores de terra.
Os dados obtidos no CEDEC e no LabSis da UFRN, além da oferta de palestra sobre a ocorrência dos terremotos, sobre as escalas de mensuração e os procedimentos a serem tomados em casos de ocorrência de tremores de terra foram de fundamental importância para o desenvolvimento da disciplina ofertada.

Ao final da disciplina os estudantes participaram de uma culminância na qual expuseram os conhecimentos adquiridos e sua aplicabilidade à sociedade, maquete mostrada na Fig. 2. Após essa etapa foram aplicados questionários estruturados aos estudantes como objetivo de investigar qual o grau de conhecimento sobre as mudanças climáticas e sobre a redução da vulnerabilidade e, consequentemente, dos riscos sofridos diante de um desastre provocado por um terremoto.

\section{Resultados e Discussões}

Nas figuras a seguir são mostrados os resultados das análises das respostas obtidas com a aplicação do questionário investigativo aos estudantes. Os resultados mostram que que $100 \%$ (cem por cento) dos participantes da disciplina afirmam ter tido aprendizagem de novos conhecimentos sobre os sismos (terremotos).

Após as afirmativas, os participantes da pesquisa podiam escolher dentre as opções postas na pergunta (descrita na Fig. 3) referente à quais os novos conhecimentos 


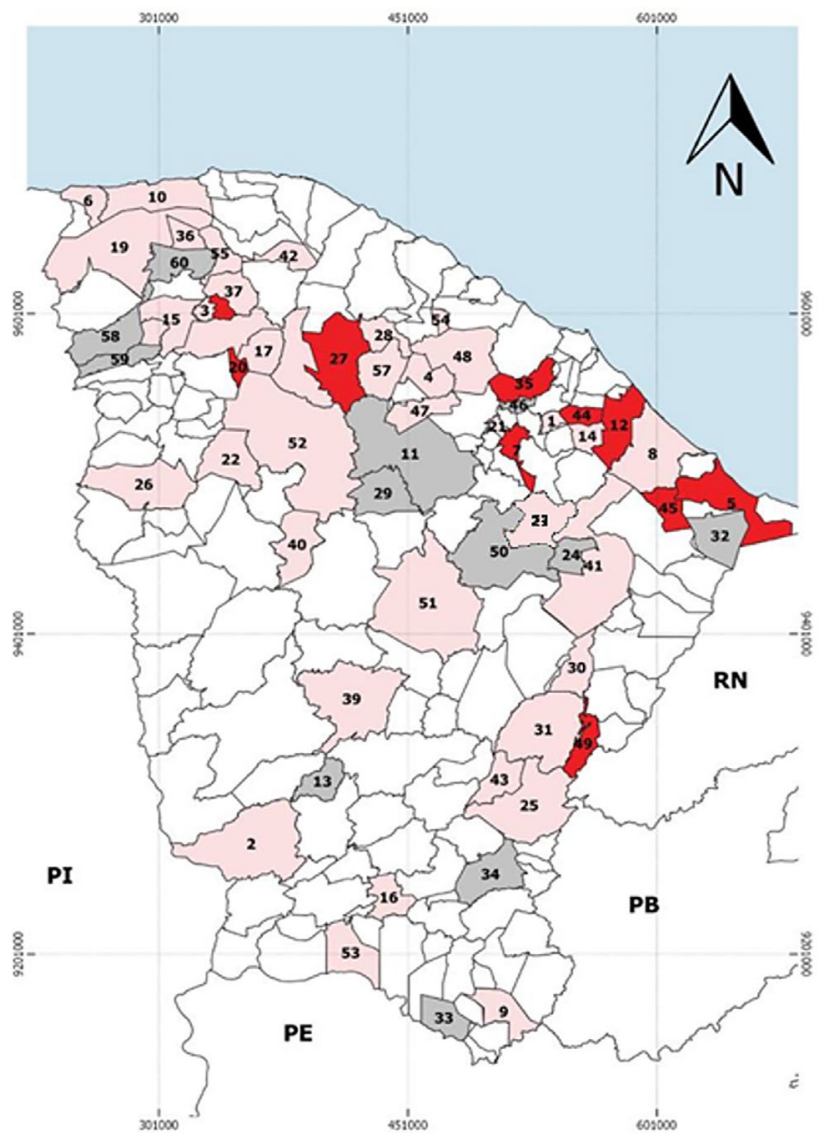

Fig. 1 - Ocorrência de eventos sísmicos no Ceará (Em vermelho estão os registros de sismos com magnitude igual ou maior a 4,0 na escala Richter, em rosa estão os sismos com magnitudes menores que 4,0 e em cinza os sem magnitude confirmada). Fonte: Coordenadoria Estadual de Defesa Civil do Ceará - CEDEC.

sobre sismos (terremotos) foram adquiridos ao final da disciplina ofertada. As respostas obtidas mostram que todas as alternativas ofertadas aos participantes foram marcadas como novos conhecimentos adquiridos na disciplina, destacando-se as ações preventivas para evitar danos humanos e materiais, descrita na alternativa (E), que foi apontada por $94 \%$ dos participantes e a compreensão sobra a sismicidade brasileira e cearense, alternativa (D),

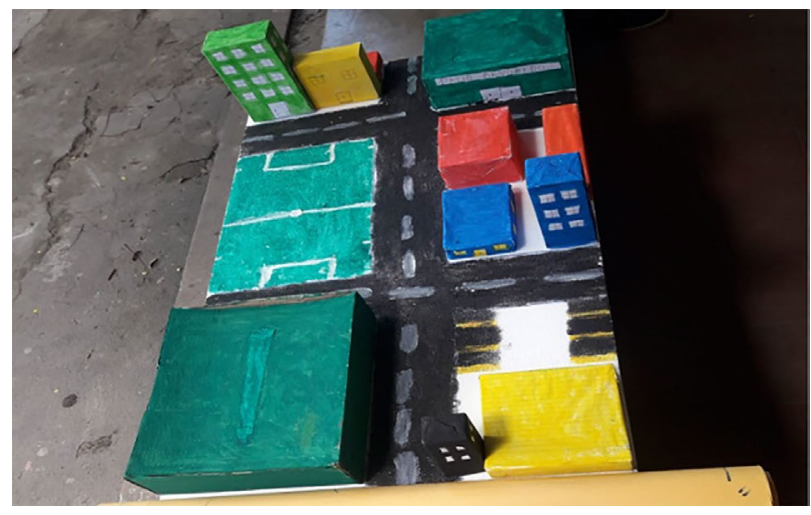

Figura 2 - Maquete elaborada pelos estudantes para simular os efeitos de um terremoto e demonstrar a maneira correta de agir durante o mesmo, apresentada na culminância da disciplina eletiva. Fonte: Registro fotográfico da disciplina "No Ceará tem disso, sim!".

apontada por $76 \%$ dos estudantes participantes da pesquisa.

Os conceitos básicos sobre sismos, escalas sísmicas, epicentro e hipocentro, descritos nas alternativas (C) e (A), foram elencados como novos conhecimentos adquiridos por $64 \%$ e $61 \%$ dos estudantes participantes da pesquisa, respectivamente. Não menos importante para a compreensão dos sismos, as características dos sismos nas regiões de borda de placa e nas regiões intraplaca, descrito na alternativa (B), foi a alternativa escolhida por $48 \%$ dos estudantes que participaram da disciplina e da pesquisa.

Os resultados obtidos evidenciam que no ensino fundamental o conteúdo sobre terremoto é abordado de forma superficial, geralmente, sendo tratados o seu conceito, as escalas de mensuração, definições de epicentro e hipocentro e características gerais de seus efeitos em regiões de bordas de placa e de intraplaca. De acordo com a grade curricular das disciplinas de Ciências e Geografia, os estudantes não são apresentados no meio escolar às formas de prevenção de desastres que possam ser causados por ocorrência de sismos.

A terceira pergunta objetivou investigar se houve mudança na concepção prévia dos estudantes sobre a ocorrência de sismos no Brasil e no Ceará. Os resultados

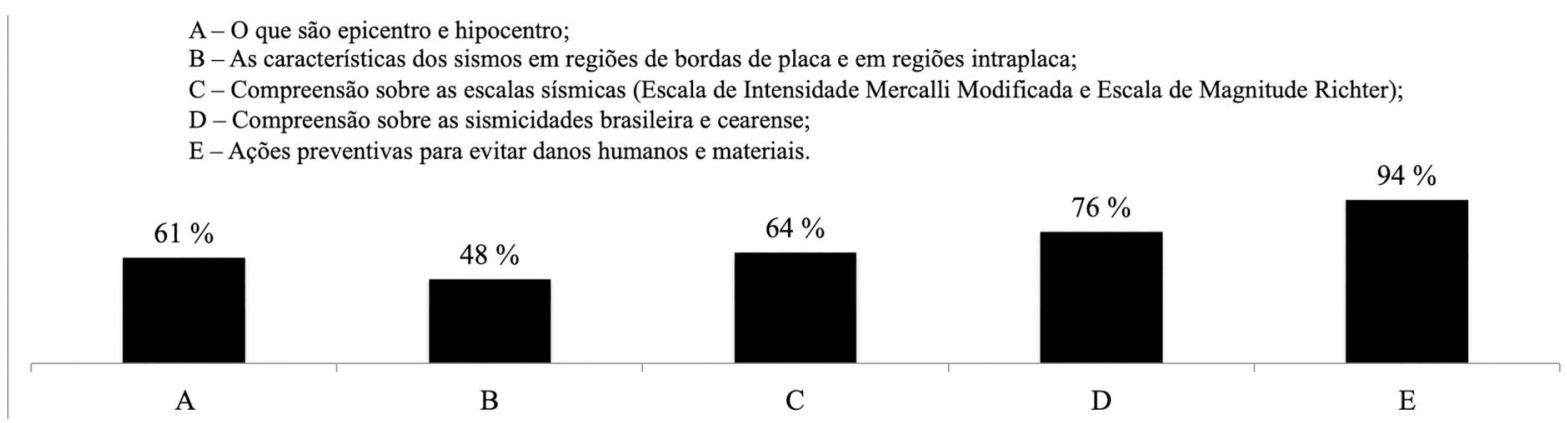

Figura 3 - Respostas ao questionário: Conceitos básicos sobre sismos. Fonte: Registro da disciplina "No Ceará tem disso, sim!". 
obtidos como respostas dessa pergunta mostraram que todos os estudantes participantes afirmam que compreenderam a ocorrência de inúmeros sismos, de pequenas a moderadas magnitudes no país e no Ceará, bem como a ocorrência de alguns raros sismos de magnitude igual ou superior a 6,0 na escala Richter que podem afetar a vida da população. Cabe aqui mencionar que segundo Preve, D’Espindula e Valdati (2017) “[...] o desconhecimento da população para com a sismicidade [...] potencializa os danos e possibilita a geração de desastres durante e após a ocorrência de sismos de magnitude moderada."

Assim, seguiu-se a sugestão de Preve, D'Espindula e Valdati (2017) sobre a relevância da aplicação de programas educacionais nas escolas, destacando a assistência a comunidades mais vulneráveis, com informações a respeito de sismos e comportamentos indicados diante da manifestação de um abalo sísmico.

Na Fig. 4 apresenta-se as respostas obtidas na pergunta em que se objetivou investigar sobre as ações a serem tomadas durante a ocorrência dos tremores de terra. Ressalta-se que aos participantes foi dada a oportunidade de marcar mais de uma opção como resposta da pergunta. Observa-se que 97\% dos participantes responderam corretamente que devem afastar-se de objetos que possam cair. Em adição, observa-se que $85 \%$ dos participantes, acertadamente, afirmam que devem procurar ficar debaixo de mesa ou objetos de material resistente e também se preocuparam em desligar o fornecimento do gás de cozinha, descritos nas alternativas (D) e (E).

Ressalta-se que, analisando-se as respostas apresentadas a essa pergunta, tem-se a confirmação das respostas encontradas anteriormente em que os estudantes participantes da pesquisa afirmam ter compreendido os conceitos básicos sobre sismos e das ações preventivas adotadas para mitigar os danos ocorridos associados à ocorrência dos sismos (terremotos).

Essa repercussão é fundamental, na medida em que confirmamos que os estudantes incorporaram saberes essenciais para o enfrentamento de situações de ocorrência de sismos, fortalecendo a constatação de que houve uma diminuição da vulnerabilidade do grupo de estudantes que fizeram parte da presente pesquisa.
Os resultados obtidos também mostram que 94\% dos participantes da pesquisa afirmam acreditar que as mudanças climáticas foram e são provocadas por ações antrópicas (Fig. 5a). Concepções que corroboram com as reflexões de Lima (2013): "Sabe-se que a profunda crise socioambiental que está instaurada no mundo contemporâneo, desencadeada pela ação antrópica de quebra do sinergismo ambiental, desponta como um tema pungente para discussão em toda a sociedade".

Em adição, encontra-se que $97 \%$ dos estudantes afirmam que se o aquecimento global continuar aumentando pode-se observar o aumento da frequência de ocorrência de desastres naturais (Fig. 5b) e em específico os desastres naturais relacionados com a ocorrência de terremotos que causam além de prejuízos materiais, a perda de vidas humanas.

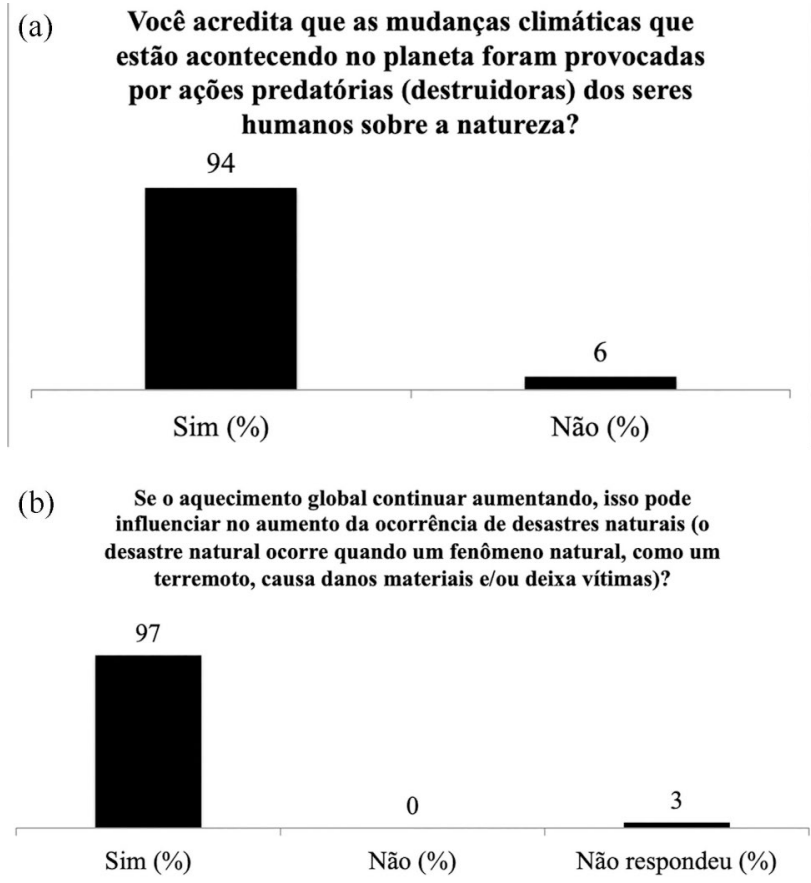

Figura 5 - Respostas ao questionário investigativo: Concepção sobre a relação entre mudanças climáticas e ações antrópicas e sobre a relação entre aquecimento global e o aumento da ocorrência de sismos. Fonte: Registro da disciplina "No Ceará tem disso, sim!".

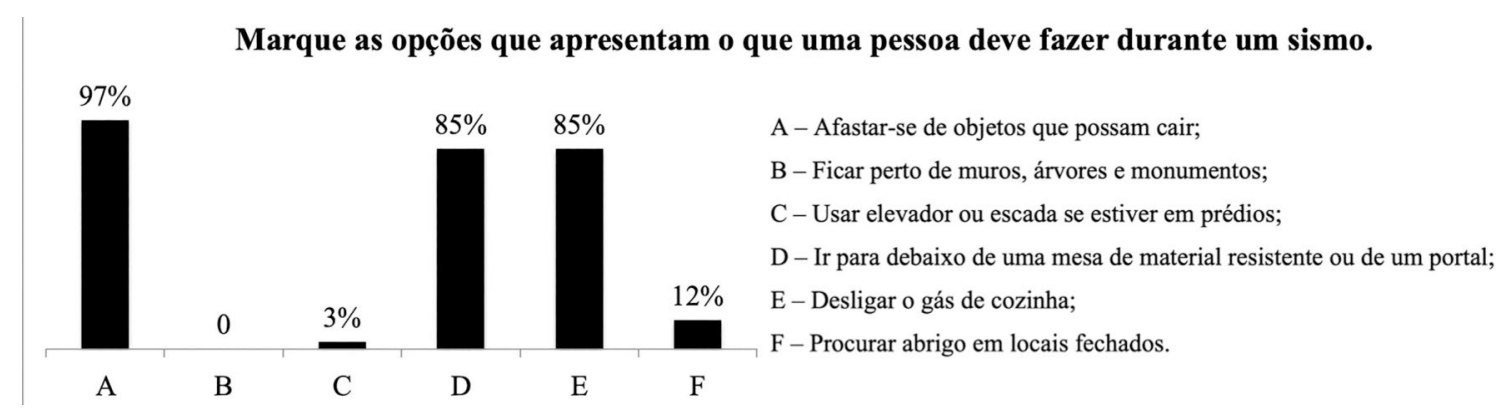

Figura 4 - Respostas ao questionário investigativo: Ações preventivas para mitigar os danos em ocorrências de sismos. Fonte: Registro da disciplina "No Ceará tem disso, sim!". 
Investigou-se, também, se os estudantes participantes da pesquisa, após o conhecimento adquirido na disciplina, seriam capazes de identificar os fenômenos naturais que podem se tornar mais frequentes devido ao aquecimento global e a intensificação das mudanças climáticas. Novamente, foi facultado aos participantes a escolha de mais de uma opção dentre as ofertadas para a escolha nos itens contidos na pergunta. Os resultados mostram que os estudantes associaram em sua maioria (82\%) o aumento do aquecimento global com o aumento da ocorrência de enchentes e terremos marcaram os itens (C) e (D) da Fig. 6, respectivamente. Em adição, tem-se que $64 \%$ apontam que se pode ter aumento de ocorrência dos tsunamis, $58 \%$ das secas, $42 \%$ dos furacões, $36 \%$ de avalanches, $33 \%$ das erupções vulcânicas e $12 \%$ das avalanches (Fig. 6).

Assim, a hipótese para a obtenção dessas respostas é que, além dos conhecimentos adquiridos na disciplina, os estudantes participantes da pesquisa, que vivem em uma região litorânea, mas com grande proximidade a região semiárida do nordeste brasileiro, tenham usado o conhecimento prévio e suas vivências com a ocorrência desses desastres naturais (secas e enchentes).

As respostas sobre a concepção dos estudantes sobre os hábitos que podem ser adotados pela sociedade para diminuir a influência das ações antrópicas no avanço dos cenários de emissões de gases de efeito estufa e, consequentemente, do aquecimento global e das mudanças climáticas do planeta, é mostrada na Fig. 7. Assim, pode-se afirmar que, em geral, os participantes demonstram consciência ambiental, pois a maioria das respostas eleitas, entre as quatorze opções disponíveis, foram as que descrevem hábitos de consumo consciente, como a diminuição do uso de combustíveis fósseis (94\%), a utilização de fontes de energias renováveis ( $85 \%$ ), a diminuição do desmatamento $(91 \%)$, o consumo consciente dos recursos naturais $(82 \%)$. Evidenciando a concepção da necessidade de se implantar um modelo de desenvolvimento sustentável na sociedade atual.

\section{Conclusões}

Diante dos registros e da realidade das mudanças climáticas, dos sismos e da intensa atividade sísmica no território cearense, através do conhecimento adquirido nas aulas e palestra proporcionadas na disciplina "No Ceará tem disso, sim!", as concepções dos estudantes, registradas através de respostas aos questionários investigativos e da vivência na disciplina, são significativas, pois demonstram que perceberam que estão expostos aos perigos (desastres) relacionados as mudanças no clima e a atividade sísmica da região. Em adição, é possível identificar

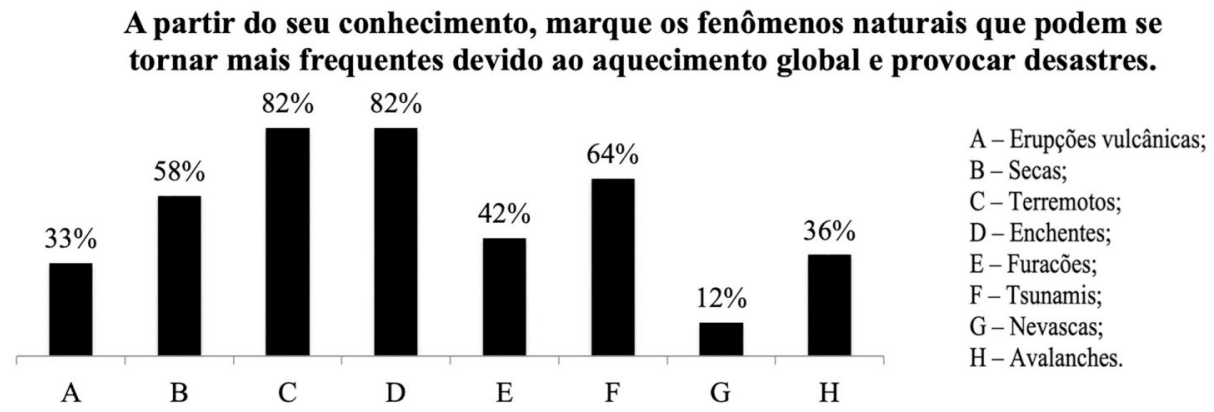

Figura 6 - Respostas ao questionário investigativo: Concepção sobre a relação entre aquecimento global e o aumento da ocorrência de desastres naturais. Fonte: Registro da disciplina "No Ceará tem disso, sim!”.

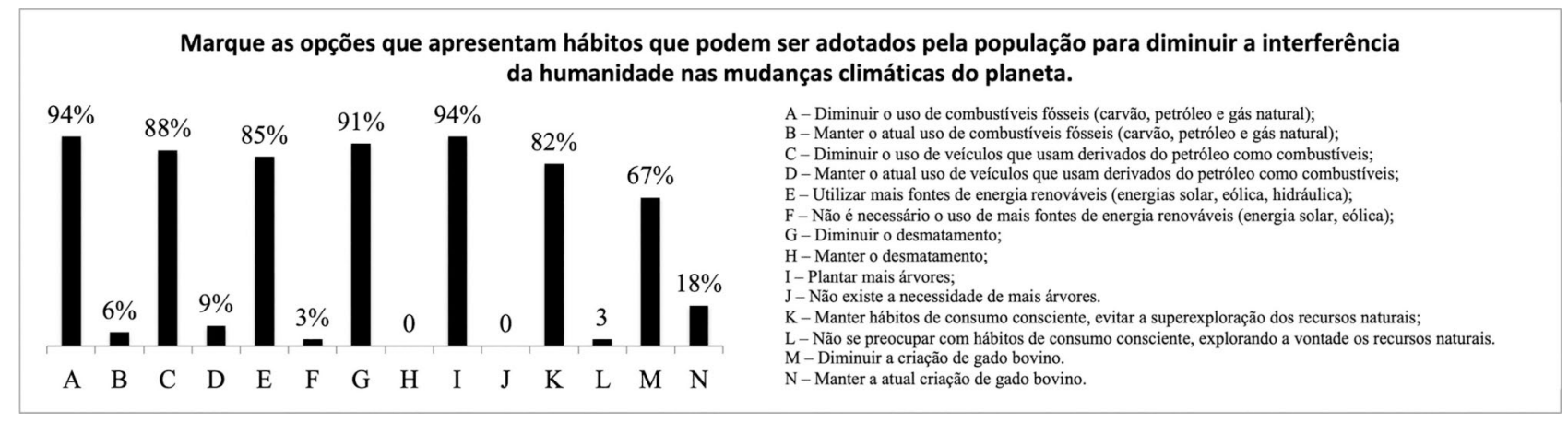

Figura 7 - Respostas ao questionário investigativo: Concepção sobre hábitos de consumo e redução da interferência antrópica nas mudanças climáticas planetárias. Fonte: Registro da disciplina "No Ceará tem disso, sim!". 
nesses estudantes a preocupação, em forma de consciência ambiental, sobre o que é preciso fazer para conviver com essa realidade de modo preventivo e ativo, sabendo se portar corretamente diante da ocorrência de desastres, naturais ou não.

O processo de desenvolvimento da disciplina "No Ceará tem disso, sim!" foi enriquecedor, pois se pode perceber que os estudantes se colocaram como agentes do fazer e deram várias ideias para a realização do momento de culminância, que foram implementadas em grupos, como a construção da maquete de simulação de sismos e das consequências de desastres dessa natureza, bem como de um plano de ação para enfrentamento e mitigação dos efeitos associados a esses desastres.

Os resultados obtidos com as respostas aos questionários e as observações realizadas na culminância da disciplina, que se insere como proposta pedagógica libertadora, utilizando um processo cooperativo de ensinoaprendizagem através do compartilhar e incentivo a apropriação de conhecimentos sobre os sismos e as mudanças climáticas, levam a concordar com a afirmativa de Nelson Mandela "A educação é a arma mais poderosa que você pode usar para mudar o mundo".

Assim, ressalta-se que o tempo, o afeto e a dedicação que professores e professoras destinam aos seus estudantes serão de grande importância para a formação de uma sociedade com princípios éticos e responsáveis, e que formarão indivíduos capazes de tomar atitudes que possam contribuir para as melhores condições de vida nas comunidades.

\section{Referências}

CORREIA, P.B. Origem dos terremotos no Nordeste. Com Ciência, 2010. Disponível em: http://www.comciencia.br/ comciencia/handler.php? section $=8 \&$ edicao $=55 \& \mathrm{id}=694$. Acesso em: 10 jun. 2018.

BASE NACIONAL COMUM CURRICULAR. A Base. Disponível em: http://basenacionalcomum.mec.gov.br/a-base. Acesso em: 19 nov. 2019.

BASE NACIONAL COMUM CURRICULAR. Histórico. Disponível em: http://basenacionalcomum.mec.gov.br/histor ico. Acesso em: 19 nov. 2019.

DEFESA CIVIL. Tremor de Terra: Saiba Como Agir. Disponível em: https://drive.google.com/file/d/ 0B2nxZNBXnLuqT2w2dWQ2R0M1N0k/view. Acesso em: 23 jul. 2019.

FREIRE, P. Pedagogia da Autonomia: Saberes necessários à prática educativa. São Paulo: Paz e Terra, 1996.
FREITAS, C.M.; CARVALHO, M.L.; XIMENES, E.F.; ARRAES, E.F.; GOMES, J.O. Vulnerabilidade socioambiental, redução de riscos de desastres e construção da resiliência: lições do terremoto no Haiti e das chuvas fortes na Região Serrana, Brasil. Ciência \& Saúde Coletiva, v. 17, n. 6, p. 1577-1586, 2012.

HAMPEL, A.; HETZEL, R.; MANIATIS, G. Response of faults to climate-driven changes in ice and water volumes on Earth's surface. Philosophical Transactions of the Royal Society A, v. 368, n. 1, p. 2501-2517, 2010.

HEKI, k. Snow load and seasonal variation of earthquake occurrence in Japan. Earth and Planetary Science Letters, v. 207, n. 1, p. 159-164, 2003.

IAFFALDANO, G.; HUSSON, L.; BUNGE, H. Monsoon speeds up Indian plate motion. Earth and Planetary Science Letters, v. 304, n. 1, p. 503-510, 2011.

KRENAK, A. Ideias Para Adiar o Fim do Mundo. São Paulo: Companhia das Letras, 2019.

LIMA, I.B. (Org.). Didática, Educação Ambiental e Ensino de Ciências e Matemática: Múltiplos Olhares. Fortaleza: EdUECE, 306 p., 2013.

LIU, C.; LINDE, A. T.; SACKS, I. S. Slow earthquakes triggered by typhoons. Nature, v. 459, n. 1, p. 833-836. 2009.

MCGUIRE, B. Potential for a hazardous geospheric response to projected future climate changes. Philosophical Transactions of the Royal Society A, v. 368, n. 1, p. 2317-2345. 2010.

MELO, F.C.B. A importância da Educação Comunitária para o Enfrentamento de Abalos Sísmicos. Dissertação de Mestrado em Ciências da Educação, Florida Christian University, Orlando, 110 p., 2017.

PREVE, W.S.; D'ESPINDULA, G.P. C.; VALDATI, J. Abalos Sísmicos Moderados no Brasil: Um levantamento dos eventos registrados nos séculos XX e XXI e a difusão de medidas preventivas. I Congresso de Geografia Física e XVII Simpósio Brasileiro de Geografia Física Aplicada, 2017.

RUBINSTEIN. J.L.; GOMBERG, J.; VIDALE, J.E.; WECH, A.G.; KAO, H.; CREAGER, K.C.; ROGERS, G. Seismic wave triggering of nonvolcanic tremor, episodic tremor and slip, and earthquakes on Vancouver Island. Journal of Geophysical Reasearch, v. 114, n. 1, p. 1-22, 2009.

TAKEYA, M. João Câmara, 1986: os abalos sísmicos e seus efeitos. Natal: Sebo Vermelho Edições, 232 p., 2016.

VELOSO, J.A.V. O Terremoto Que Mexeu Com o Brasil. Brasília: Thesaurus, 2012.

License information: This is an open-access article distributed under the terms of the Creative Commons Attribution License (type CC-BY), which permits unrestricted use, distribution and reproduction in any medium, provided the original article is properly cited. 